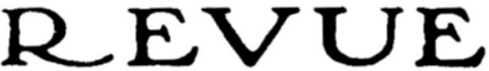

\title{
INTERNATIONALE DE LA
}
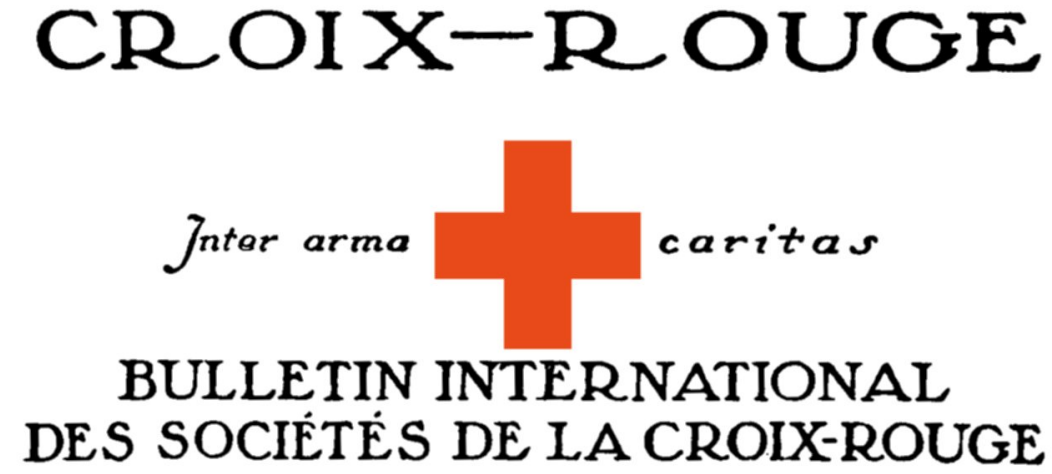

paraissant à la fin de chaque mois

T. LXXII, No 462

SOMMAIRE :

COMITÉ INTERNATIONAL DE LA CROIX-ROUGE. - Le Comité international de la Croix-Rouge et la guerre, 93. - La Commission de coordination du Comité international de la Croix-Rouge, 96. - Chronique de l'Agence centrale des prisonniers de guerre, 99. - Missions du Comité international de la Croix-Rouge : Visites des camps de prisonniers de guerre en Angleterre, faites par M. R.-A. Haccius, 112 ; visites de camps de prisonniers de guerre en Allemagne, faites par les Drs Pierre Descœudres et Louis Roulet, 121.

Premier lieutenant de PERROT, aumónier protestant au Commissariat fédéral de l'internement. - L'internement en Suisse, 1940-1941 (hors-texte), 132.

PROTECTION DES POPULATIONS CIVILES. - Protection alimentaire des populations civiles, 148. - Publication allemande, 153. - Publication américaine, 156. - Publication yougoslave, 1566.

CHRONIQUE. - Une histoire philatélique de la Croix-Rouge, 158. - Collaboration panaméricaine en matière d'hygiène, 159. - Institution de la "Journée panaméricaine de la santé ", 160.

BIBLIOGRAPHIE. - Les internés en Suisse tels qu'ils nous ont vus, 161. I travers Jes revues, 161 .

BLLLETIN INTERNATIONAL DES SOCIETÉS DE LA CROIX-ROUGE (voir la $4^{\mathrm{e}}$ page de la couverture), 165.

\section{GENEVE}




\section{Comité international de la Croix-Rouge \\ à Genève}

MM. Huber, Max, docteur en droit, ancien président de la Cour permanente de justice internationale, (I923), président.

Barbey-Ador, Frédéric, ancien ministre de Suisse en Belgique, (I9I5).

Des Gouttes, Paul, docteur en droit, avocat, (I9I8).

Mme Ed. Frick-Cramer, (IgI8).

MM. Chenevière, Jacques, homme de lettres, (I 1 I9).

Logoz, Paul, docteur en droit, professeur de droit pénal à l'Université de Genève, colonel d'état-major général, (I92I).

Mıle Ferrière, Suzanne, directrice-adjointe de l'International Migration Service, (I924).

MM. de Haller, Rodolphe, banquier, (I924), trésorier.

Audeoud, G. E., $D^{\boldsymbol{r}}$, colonel, ancien médecin de division de l'armée suisse, (I925).

Patry, Georges, Dr, colonel, ancien médecin de division, attaché à l'état-major de l'armée, (I929).

Mile Odier, Lucie, ex-chef du Service des infirmières-visiteuses de la Croix-Rouge genevoise, (I930).

MM. de Planta, Franz, colonel, (r930).

Favre, Guillaume, colonel divisionnaire, (I932).

Zangger, Heinrich, Dr en médecine, professeur à l'Université et directeur de l'Institut de médecine légale de Zurich, (I932).

Burckhardt, Carl J., docteur en philosophie et en droit, (I933).

Micheli, Jacques-Barthélemy, ingénieur, (I935).

Wagnière, Georges, docteur en droit, ancien ministre de Suisse à Rome (I936).

Martin, Paul-E., docteur ès lettres, professeur d'histoire à l'Université de Genève, (1937).

Yung, Walter, docteur en droit, (I937).

Chapuisat, Edouard, docteur ès lettres, (1938).

M1le Bordier, Renée, infirmière chef au "Bon Secours ", (1938).

MM. Cramer, Alec, Dr, colonel, (r938).

Bodmer, Martin, (I940).

Etter, Philippe, conseiller fédéral (I940).

Membres honoraires

MM. Boissier, Edmond, colonel, (IgI4).

Bouvier, Bernard, professeur honoraire de l'Université de Genève, (I9I9).

Cramer, Lusien, docteur en droit, (I92I). 